\title{
Detection of outliers in $B L(1,1,1,1)$ models using least squares method
}

\author{
Ibrahim Mohamed \\ Institut Sains Matematik \\ Universiti Malaya \\ 50603 Kuala Lumpur \\ E-mail: imohamed@um.edu.my \\ Azami Zaharim \\ Jabatan Senibina, Fakulti Kejuruteraan \\ Universiti Kebangsaan Malaysia, Bangi, Selangor \\ E-mail: azami@vlsi.eng.ukm.my \\ Muhammad Sahar Yahya \\ Pusat Asasi Sains, Universiti Malaya \\ 50603 Kuala Lumpur \\ E-mail: mohdsahar@um.edu.my \\ Mohammad Said Zainol \\ Fakulti Teknologi Maklumat dan Sains Kuantitatif \\ Universiti Teknologi MARA \\ 47000 Shah Alam, Selangor \\ E-mail: mankidal@streamyx.com
}

\begin{abstract}
In the literature, various nonlinear time series data was shown to exist. As a result, studies on nonlinear models have been carried out. One of them is bilinear model. Further, there is a possibility that outliers may exist in the data. In this article, the possibility of an outlier appear in a special case of bilinear model, $\mathrm{BL}(1,1,1,1)$ is investigated. An outlier detection procedure is proposed.
\end{abstract}

\section{Introduction}

Ruberti et al. [1972] and Mohler [1973] initiated the idea of bilinear models with applications on control theory. A real in-depth statistical study was started by Granger and Anderson [1978a]. They presented various types of bilinear models and discussed the invertibility and stationarity properties of the models. They also showed that bilinear model performs well compared to linear model when applied to the Wölfer sunspot data and the IBM daily common stock closing prices as available in Box and Jenkins [1976]. Another interesting feature of bilinear model is the fact that it is merely an extension of the linear ARMA model as well as being a simplified case of nonlinear Volterra series expansions (Weiner [1958]).

Most discussion on detection of outliers is for the linear case. As for bilinear model, only Chen [1996] and Zaharim [1996] had explored the area. Chen used 
the Gibbs sampling method for general bilinear model but only considered one type of outlier only, the additive outlier. On the other hand, Zaharim used the least squares method for simple bilinear model to detect four type of outliers, the additive outlier (AO), innovational outlier (IO), temporary change (TC) and level change (LC). In this article, work by Zaharim [1996] is extended for $\operatorname{BL}(1,1,1,1)$. It is shown that the detection procedure performs well in detecting each type of outlier.

\section{Methodology}

$\mathrm{A} B L(1,1,1,1)$ model is given by:

$$
Y_{t}=a Y_{t-1}+c e_{t-1}+b Y_{t-1} e_{t-1}+e_{t}
$$

where $a, b$ and $c$ are any real number satisfying the stationary condition of the model whereas $Y_{t}$ and $e_{t}$ are the observation and residual respectively, $t=1$, $2,3, \ldots$ The $e_{t}$ 's are assumed to follow normal distribution with mean zero and precision $\tau, \tau>0$.

\section{Model estimation method}

The estimation method employed is the nonlinear least squares method as found in Priestly [1991]. The method is recursive in nature and the estimation obtained when a necessary condition is achieved. The method is extended for $\operatorname{BL}(1,1,1,1)$ model.

\section{Measure of outlier effect}

In order to detect outliers, the measures of outlier effect are derived using the least squares method by minimising

$$
S=\sum_{t=1}^{n} e_{t}^{2}
$$

The measures of effect for each type of outliers are obtained and denoted as $\hat{\omega}_{T P}$ where TP can be either AO, IO, TC or LC. To find the variance of the measures, bootstrap method is employed. The test statistics employed here are the standardized measure of each outlier effect using the bootstrap mean and standard deviation, denoted by $\hat{\tau}_{T P, t} \cdot$.

In general, the time point where an outlier occurs is unknown. Alternatively, the values of the test statistics can be obtained at every time point $t=1,2, \ldots, n$. Hence, the test statistics further leads to the following test criteria: 


$$
\hat{\eta}_{T P}=\max _{t=1, \ldots, n}\left\{\left|\hat{\tau}_{T P, t}\right|\right\} \text {. }
$$

To identify the type of outlier at a particular point $t$ in $\mathrm{BL}(1,1,1,1)$ model, the following rule is considered.

$$
\eta_{t}=\max \left\{\left|\hat{\tau}_{I O, t}\right|,\left|\hat{\tau}_{A O, t}\right|,\left|\hat{\tau}_{T C, t}\right|,\left|\hat{\tau}_{L C, t}\right|\right\} .
$$

Given a pre-determined critical value $\mathrm{C}$, if $\eta_{t}=\left|\tau_{T P, t}\right|>C$, then there is a possibility of a type TP at time $t, T P$ can be IO, AO, TC or LC.

\section{Result}

In general, simulation study showed that the proposed outlier detection procedure for $\mathrm{BL}(1,1,1,1)$ models performs well. The procedure had also been applied on real data set and were able to detect apparent outliers.

\section{References}

1. CHEN, C.W.S., (1997) Detection of additive outliers in bilinear time series. Computational Statistics and Data Analysis, 24, 283-294.

2. GRANGER, C.W.J. and ANDERSEN, A.P., (1978a) Introduction to Bilinear Time Series Models. Gottinge: Vandenhoeck and Ruprecht.

3. MOHLER, R.R., (1973) Bilinear Control Process. New York: Academic Press.

4. PRIESTLY, M.B., (1991) Non-linear and Non-stationary Time Series Analysis. San

5. RUBERTI, A., ISIDORI, A. and D'ALLESANDRO, P. (1972) Theory of Bilinear Dynamical System. Berlin: Springer-Verlag.

6. ZAHARIM, A., (1996) Outliers and Change Points in Time Series Data. PhD Thesis, University of Newcastle Upon Tyne. 